\title{
Ocular infection with Gliocladium species-report of a case
}

Ramesh Venkatesh ${ }^{1 *}$, Prachi Gurav', Manisha Agarwall, Neelam Sapra ${ }^{1}$ and Prachi Abhishek Dave ${ }^{1}$

\begin{abstract}
Purpose: The purpose of this study is to report a case of ocular infection with Gliocladium species due to an exposed scleral buckle.

Design: Interventional case report was used as the study design.

Methods: A 60-year-old diabetic male patient presented with persistent pain, redness, and discharge in his left eye since 2 months. He had been treated previously with both topical and systemic steroids for a diagnosis of autoimmune scleritis. He had undergone scleral buckling surgery with cryotherapy for an inferior rhegmatogenous retinal detachment in the past. His best-corrected visual acuity was 6/6, N6 and 6/6, N6 in the right and left eyes, respectively. Retraction of the left lower lid revealed an exposed scleral buckle with an overlying necrotic conjunctiva. Scleral buckle removal was done. Microbiological examination showed Gliocladium species growing on blood agar and Sabouraud dextrose agar. Treatment was started with topical antifungal medication and oral antibiotics.

Results: Following treatment, signs of infection showed resolution. Patient underwent retinal reattachment surgery with favorable anatomic and visual outcome.

Conclusion: Ocular infection with Gliocladium species has not been previously reported. Poor response to steroids and uncontrolled diabetes should make the clinician aware of a possible fungal infection. Removal of the scleral buckle, identification of the causative organism, and use of appropriate antibiotics are important for the accurate management of the case.
\end{abstract}

Keywords: Buckle infection, Gliocladium species, Fungus

\section{Findings} Introduction

In the current era, scleral buckling with explants still remains an important and effective technique to attach the retina. Extrusion and infection of the scleral buckle (SB) are the two most common indications for SB removal [1]. Many organisms, generally bacteria, have been implicated as a cause of SB infection. Fungus as a cause of SB infection is rare. We report a case of ocular infection in an old diabetic man caused by a rare fungus called Gliocladium species due to an exposed SB. This happens to be the first reported case of ocular infection due to Gliocladium species in literature to the best of our knowledge.

\footnotetext{
* Correspondence: vramesh80@yahoo.com

${ }^{1}$ Retina \& Vitreous Department, Dr Shroff Charity Eye Hospital, 5027,

Kedarnath Road, Daryaganj, New Delhi 110002, India

Full list of author information is available at the end of the article
}

\section{Case description}

A 60-year-old male was referred to the retina clinic of a tertiary eye care hospital with complaints of persistent pain, watering, and redness in the left eye for the past 2 months. He was treated elsewhere with topical and oral corticosteroids for a diagnosis of possible autoimmune scleritis. He was a known case of insulindependent diabetes mellitus with uncontrolled blood sugar at the time of presentation to the retina clinic. He underwent scleral buckling surgery with cryotherapy in that eye for an inferior rhegmatogenous retinal detachment elsewhere 2 years ago. Operative notes of the left eye suggested a no. $276 \mathrm{SB}$ explant placed in the inferior quadrant along with a $360^{\circ}$ encircling band. Examination revealed a best-corrected visual acuity (BCVA) of $6 / 6$, N6 and 6/6, N6 in the right (RE) and left eyes (LE), respectively. Anterior segment examination of the RE 
was normal. Nuclear cataract was noted in the RE. Fundus examination of the RE was normal. Lid edema and conjunctival congestion was noted in the LE. Careful retraction of the left lower lid showed a necrotic conjunctiva in the infero-temporal quadrant with an underlying exposed SB element. Patient was pseudophakic in the LE. Fundus examination showed a shallow recurrent inferior retinal detachment in the LE. However, the retina at the macula was attached. A diagnosis of exposed and infected SB was made, and a decision to explant the SB element along with scleral patch graft was taken. Cefotaxime injection $1 \mathrm{~g}$ i.v. twice a day and gentamicin injection $60 \mathrm{mg}$ i.v. thrice a day were given a day before the surgery. Intraoperatively, the $\mathrm{SB}$ along with the encircling band was removed under local anesthesia with maximal sedation. The buckle material was a solid silicone rubber which was removed after cutting the anchoring sutures of the SB to the sclera. No evidence of scleral thinning was noted, and the globe was well formed. Scleral patch graft was not required. Postoperatively, the patient was started on empirical antibiotics; tablet ciprofloxacin $750 \mathrm{mg}$ twice a day, topical moxifloxacin eye drops 10 times a day, and topical lubricants four times a day. The scleral buckle grew Gliocladium species on both blood agar and Sabouraud dextrose agar (SDA). Microscopic examination showed hyaline hyphae and conidiophores suggestive of Gliocladium species (Fig. 1). Based on the culture growth, topical antibiotics were changed to topical voriconazole eye drops 10 times a day, and topical lubricants four times a day were continued. Post-operative examination of the left eye in 1 month showed a quiet eye with no conjunctival congestion. Fundus evaluation of the left eye showed an inferior macula-on retinal detachment for which he underwent three port pars plana vitrectomy with endolaser and gas endotamponade. On his last follow-up visit, his BCVA in the left eye remained stable at 6/6, N6 with a completely attached retina.

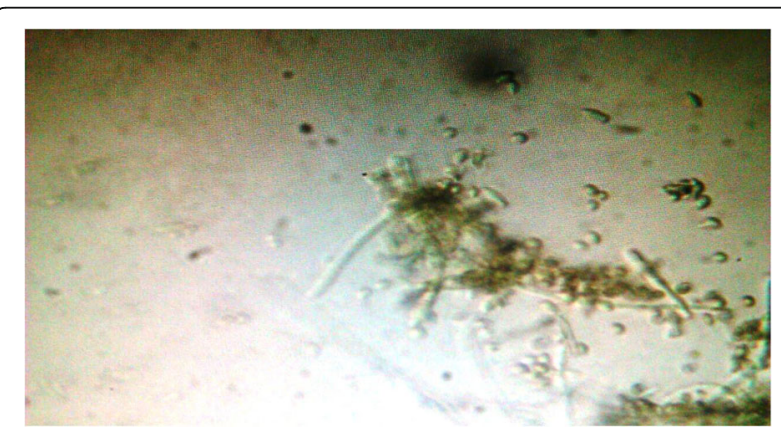

Fig. 1 Microscopic examination of Gliocladium species. Microscopic examination shows the hyaline hyphae, conidiophores, and conidia borne from hyaline phialides suggestive of Gliocladium species

\section{Discussion}

SB infection and extrusion remain fairly uncommon complications following scleral buckling surgery. Their estimated incidence varies from 0.2 to $5.6 \%$ [2-6]. Coagulase-positive and coagulase-negative Staphylococci are implicated as the most common organisms causing SB infection (70 to $90 \%$ of cases) [6]. However, rarer cases with infections due to atypical mycobacterium, corynebacteria, and fungi have been reported [7]. In a series of 132 cases of SB infections studied by Chhablani et al. [2], only 15 cases were caused by fungi. The most common fungus isolated in their series was the Aspergillus species. Our patient was an elderly diabetic male, misdiagnosed as autoimmune scleritis, and treated extensively with topical and oral corticosteroids. Careful examination revealed an exposed SB element with an overlying necrotic conjunctiva. Culture positivity was noted in 5 days. The SB grew Gliocladium species on culture media. Gliocladium is a mitosporic, filamentous fungus. Commonly occurring species include Gliocladium penicilloides, Gliocladium virens, and Gliocladium roseum. Most species of Gliocladium grow rapidly in culture producing spreading colonies with a cotton-like texture, covering a petri dish in 1 week. The colonies are initially white and cream-like but may become reddish or green as they age and sporulate. Microscopically, Gliocladium species produces hyphae, conidiophores, and conidia borne from hyaline phialides. The conidiophores are erect, dense, and have a brush-like structure which produces tapering, slimy phialides [8]. Gliocladium species is a saprophytic fungus. The necrotic conjunctiva and scleral tissue provides an excellent environment for the organism to grow. In our case, following the growth of this rare fungus, we rightly modified our treatment by adding topical voriconazole to the regime.

\section{Conclusion}

To the best of our knowledge, this is the first case report of ocular infection with Gliocladium species. Poor response to steroids and uncontrolled diabetes should make the clinician aware of a possible fungal infection. Removal of the SB, identification of the causative organism, and use of appropriate antibiotics are vital for the accurate management of the case.

\section{Abbreviations}

BCVA: Best-corrected visual acuity; i.v: Intravenous; LE: Left eye; RE: Right eye; SB: Scleral buckle; SDA: Sabouraud dextrose agar

\section{Acknowledgements}

None.

\section{Funding}




\section{Availability of data and materials}

All the data and images pertaining to the case are available with the corresponding author.

\section{Authors' contributions}

RV drafted the manuscript and critically reviewed the manuscript; PG worked on the acquisition of the data; MAA carried out the management of the case and reviewed the manuscript; NS did the reporting of the microbiological aspect of the case; and PAD made the review of the literature and reviewed the manuscript. All authors read and approved the final manuscript.

\section{Competing interests}

The authors declare that they have no competing interests.

\section{Consent for publication}

Written informed consent was obtained from the patient for the publication of this report and any accompanying images. Approval was granted to us by our own institute's IRB.

\section{Publisher's Note}

Springer Nature remains neutral with regard to jurisdictional claims in published maps and institutional affiliations.

\section{Author details}

'Retina \& Vitreous Department, Dr Shroff Charity Eye Hospital, 5027, Kedarnath Road, Daryaganj, New Delhi 110002, India. ${ }^{2}$ Ocular Microbiology Department, Dr Shroff Charity Eye Hospital, 5027, Kedarnath Road, Daryaganj, New Delhi 110002, India.

Received: 24 January 2017 Accepted: 10 March 2017

\section{Published online: 14 March 2017}

\section{References}

1. Tsui I (2012) SB removal: indications and outcomes. Surv Ophthalmol 57: 253-63

2. Chhablani J, Nayak S, Jindal A, Motukupally SR, Mathai A, Jalali S, Pappuru RR, Sharma S, Das T, Flynn HW Jr, Pathengay A (2013) SB infections: microbiological spectrum and antimicrobial susceptibility. J Ophthalmic Inflamm Infect 13(3(1)):67

3. Deutsch J, Aggarwal RK, Eagling EM (1992) Removal of scleral explant elements: a 10-year retrospective study. Eye 6(Pt 6):570-3

4. Joseph J, Pathengay A, Michael V, Raju B, Sharma S, Das T (2006) In vitro efficacy of cefazolin and povidone-iodine $5 \%$ in eradicating microbial organisms adhered to broad SBs. Clin Exp Ophthalmol 34(4):390-1

5. Pathengay A, Karosekar S, Raju B, Sharma S, Das T (2004) Hyderabad Endophthalmitis Research Group. Microbiologic spectrum and susceptibility of isolates in SB infection in India. Am J Ophthalmol 138:663-4

6. Smiddy WE, Miller D, Flynn HW Jr (1993) SB removal following retinal reattachment surgery: clinical and microbiological aspects. Ophthalmic Surg 24:440-5

7. Bakri SJ, Omar AF (2013) Delayed SB infection due to Alternaria species. Semin Ophthalmol 28:9-10

8. Miller JH, Giddens JE, Foster AA (1957) A survey of the fungi of forest and cultivated soils of Georgia. Mycologia 49(6):779-808

\section{Submit your manuscript to a SpringerOpen ${ }^{\circ}$ journal and benefit from:}

- Convenient online submission

- Rigorous peer review

- Immediate publication on acceptance

- Open access: articles freely available online

- High visibility within the field

- Retaining the copyright to your article 